Sādhanā Vol. 39, Part 6, December 2014, pp. 1387-1408. (C) Indian Academy of Sciences

\title{
Numerical modelling of multicomponent LNAPL dissolution kinetics at residual saturation in a saturated subsurface system
}

\author{
M VASUDEVAN $^{1}$, G SURESH KUMAR ${ }^{2, *}$ and \\ INDUMATHI M NAMBI ${ }^{1}$
}

${ }^{1}$ Environmental and Water Resources Engineering, Department of Civil Engineering,
Indian Institute of Technology Madras, Chennai 600 036, India
${ }^{2}$ Petroleum Engineering Programme, Department of Ocean Engineering, Indian
Institute of Technology Madras, Chennai 600 036, India
e-mail: devamv@gmail.com; gskumar@iitm.ac.in; indunambi@iitm.ac.in

MS received 28 February 2014; revised 5 May 2014; accepted 12 June 2014

\begin{abstract}
Characterization of aquifers contaminated by petroleum hydrocarbons is limited by the use of dissolution mass transfer correlations developed for single compounds without considering the effects of the mass transfer limitations in presence of other components. A one-dimensional implicit numerical model is developed for the coupled mass transfer and transport processes and the results are analysed using existing mass transfer correlations for better understanding of the single and multicomponent dissolution processes. The mass transfer coefficient in the multicomponent system is found to be more nonlinear and extending with changing slope, unlike the exponential reduction for single compound system. During the initial phase, the dissolution rate of a soluble compound is very high due to the high concentration gradient, and as dissolution progresses, its effective solubility decreases with change in mole fraction. At higher pore volumes, the mole fractions of lower solubility fractions increase which can result in higher effective solubility. The kinetics of interphase mass transfer by dissolution and sorption is favoured by coupled biodegradation. However, mass transfer limitation for more soluble compounds under the conditions of low residual saturation and low mole fraction is observed to be due to low dissolution rate coefficient rather than decreasing concentration gradient.
\end{abstract}

Keywords. Multicomponent dissolution; numerical modelling; petroleum hydrocarbons; residual saturation.

${ }^{*}$ For correspondence 


\section{Introduction}

Accidental spills and leakage of organic compounds such as petroleum hydrocarbons (PHC) are becoming the continuing source of subsurface contamination because of their inherent toxicity and partitioning tendency to various environmental compartments, especially to the aquifer material and ground water. Subsurface transport of these multicomponent organic compounds poses a significant threat to the quality of potential drinking water reservoir through continuous but slow release, finally reaching the water table, which can contribute to groundwater contamination for many decades (Kao \& Prosser 2001; Ucankus \& Unlu 2008). Following migration and subsequent removal of free phase liquid, still the organic compounds are present as entrapped non-aqueous phase liquid (NAPL) blobs occupying soil micro-pores, resulting in residual NAPL saturation, which serves as the source of mass transfer limited dissolution (Yang et al 1995; Johnson et al 2003; Liu et al 2007).

The complexity associated with dissolution mass transfer of organic compounds is closely related to their relative hydrophobic nature, distribution of the non-aqueous phase mass within the aquifer pore volume, prevailing flow and other geochemical properties of the porous medium (Saba \& Illangasekare 2000; Soga et al 2004). Uniformly distributed non-aqueous phase PHC at residual saturation in homogeneous subsurface conditions are more conducive to contaminant removal compared to adverse heterogeneous conditions. It is well-established that there is considerable limitation on interphase mass transfer when the contributing residual contaminant is occupying small interfacial area or when the flushing fluid velocity is substantially high enough to reduce the residence time (Powers et al 1994; Hamed et al 2000; Keller \& Sirivithiyapakorn 2000). Depending on the scale of the problem and mass transfer limitation considerations, various empirical mass transfer correlations were derived in terms of dimensionless numbers with suitable coefficients (Abriola 1989; Geller \& Hunt 1993; Imhoff et al 1994; Mayer \& Miller 1996; Kim \& Chrysikopoulos 1999; Nambi \& Powers 2000; Chu et al 2007; Liu et al 2007; Corapcioglu et al 2009).

Correlation developed by Nambi \& Powers (2003) is well-suited for heterogeneous lab scale systems for wide range of initial NAPL saturation, especially for high initial NAPL saturations. Similarly, Schaerlaekens et al (2000) developed correlations with three and four parameters incorporating the effect of intermittent stopping of flow on mass transfer phenomena. The correlation by Powers et al (1994) which is widely referred for uniform residual saturation in a homogeneous porous media is, however, limited in application only to similar saturation conditions. The correlation by Imhoff et al (1994) is incorporating the effect of dissolution fingering in terms of relative domain size, suggest the effect of contamination history on mass transfer coefficient, but it is substantially poor in predicting the dissolution breakthrough for laboratory scale domain. These correlations are claimed to be capable of being up-scaled to different sized NAPL source zones, but it is not clear how these mass transfer correlations perform for the purpose of simulating NAPL dissolution coupled with geo-biochemical reactions. Seagren et al (1999) showed that dissolution is enhanced the most when the time scale of the first order reaction is shorter than that of purely physical dissolution. Also, the local diffusion length is reduced for the case of reaction-coupled dissolution when compared with that of no reaction. Moreover, since there is no term representing the effect of reaction on dissolution, studies on reaction-enhanced NAPL pool dissolution indicates that this assumption is questionable.

The dissolution behaviour exhibited by a particular compound when it is the sole occupant is not sufficient for understanding its behaviour when present in a mixture, because of the variation in the effective solubility in accordance with the NAPL composition and other possible interactions resulting in non-ideal behaviour of the mixture (Gonullu 1996; Powers et al 1994; 
Mayer \& Miller 1996; Garg \& Rixey 1999; Keller \& Sirivithiyapakorn 2000; Mobile et al 2012; Burke 2012). For the multicomponent system, the transient behaviour of the mass transfer coefficient pertaining to the variations in pore velocity and volumetric saturation is significant in addition to the variability in molecular diffusion of each component. Since the petroleum fuels contain multiple components with varying physical and chemical properties, the dissolved plume of individual components can spread at different rates in accordance to the difference in effective solubility as well as differential retardation caused by sorption, even though they occupy same pore volume (Borden \& Piwoni 1992; Frind et al 1999; Prommer et al 2000; Hansen 2012; Vasudevan et al 2012). Several numerical investigations have been carried out using linear as well as nonlinear sorption isotherms in homogeneous as well as heterogeneous porous systems (Johnson et al 2003; Zhang \& Brusseau 2004; Sekhar \& Suresh Kumar 2006; Sekhar et al 2006; Suresh Kumar 2008; Suresh Kumar et al 2008; Suresh Kumar 2009; Natarajan \& Suresh Kumar 2010; Renu \& Suresh Kumar 2012; Suresh Kumar 2014). However, these properties are significant for the estimation of kinetic nature of dissolution from residually trapped sources since the interactions between various phases in the aquifer system are significant at the pore scale. In order to simulate the subsurface contamination scenario, numerical approach is preferred to handle nonlinearity constraints over simplified analytical solutions even though it is to be constructed to minimize the possible numerical error (Yang et al 1995; Molson 2000; Clement et al 2004; Chamkha 2007; Couto \& Malta 2008; Sulaymon \& Gzar 2011).

In the present study, we discuss the scenario of residually trapped non-aqueous phase petroleum hydrocarbons present at different residual saturation conditions with implications of modelling the fate and transport of aqueous concentration plume under coupled geo-biochemical reactions. The study also addresses the suitability of mass transfer correlation for modelling the dissolution process of individual components present in a mixture under the effect of coupled reactions. We also attempt to study the comparative effect of rate limitation on the dissolution mass transfer rate coefficient when the contaminant is present as single as well as in a mixture considering the complexity of physico-chemical reactions of the compounds involved.

\section{Materials and methods}

\subsection{Physical system and governing equations}

Since the flow through porous media is mainly restricted to the pore space around the immobile NAPL blobs and pore throats, there will be considerable variation in the average pore velocity. As the volume of the residual NAPL source decreases as a result of inter-phase mass transfer, there will be corresponding reduction in the interfacial area between the NAPL blob and surrounding aqueous phase. However, at the present scale of our model, the change in aqueous concentration at the downstream of the NAPL source is assumed to be not affected by the morphological change resulting from dissolution.

In order to model the contaminant plume distribution and evolution in the subsurface, the governing equation should include the effects of transport processes such as advection and dispersion, and reactive processes such as dissolution, adsorption and biodegradation. The ratelimited dissolution and sorption are represented here using first order kinetic expression, whereas the Monod equation for the biodegradation is having a mixed order. Further, in order to address the mass transfer limitations at the aqueous-soil interface, the sorption process is taken as a combination of equilibrium and kinetic processes, contributing to the surface properties of the porous media. Considering the overall effect of these mass transfer processes on the contaminant evolution within the domain, the transient transport of each dissolving component 
under steady-state uniform flow conditions is given by (Schaerlaekens et al 2000; Brauner \& Widdowson 2001);

$$
\begin{aligned}
\operatorname{Ret} \frac{\partial C_{a_{i}}}{\partial t}= & D_{L_{i}} \frac{\partial^{2} C_{a_{i}}}{\partial x^{2}}-v \frac{\partial C_{a_{i}}}{\partial x}+K_{w n_{i}}\left(C_{s a t_{i}}-C_{a_{i}}\right) \\
& -K_{m}\left[(1-f) k_{d_{i}} C_{a_{i}}-S_{i}\right]-\left[\frac{V_{\max _{i}} X_{a_{i}} C_{a_{i}}}{K_{s_{i}}+C_{a_{i}}}\right],
\end{aligned}
$$

where Ret is the retardation factor due to equilibrium sorption (calculated asRet $=1+\mathrm{f} \rho_{\mathrm{b}} k_{d} / \varphi$, where $f$ is the fraction of equilibrium sorption sites [-], $\rho_{b}$ is the bulk density of the aquifer material $\left[\mathrm{ML}^{-3}\right], k_{d}$ is the linear partitioning coefficient $\left[\mathrm{L}^{3} \mathrm{M}^{-1}\right]$ and $\phi$ is the porosity [-]); $C_{a_{i}}$ is the aqueous phase concentration of component $i\left[\mathrm{ML}^{-3}\right] ; D_{L_{i}}$ is the longitudinal dispersion coefficient $\left[\mathrm{L}^{2} \mathrm{~T}^{-1}\right.$ ] (given by $D_{L_{i}}=D_{m_{i}}+\alpha_{L} v$, where $D_{m_{i}}$ is the molecular diffusion coefficient of component $i\left[\mathrm{~L}^{2} \mathrm{~T}^{-1}\right]$ and $\alpha_{L}$ is the longitudinal dispersivity of the porous medium [L]); $v$ is the mean fluid velocity $\left[\mathrm{LT}^{-1}\right]$ (calculated as $v=q / \varphi$, where $q$ is the Darcy velocity [LT $\left.{ }^{-1}\right]$ ); $K_{w n_{i}}$ represents the lumped mass transfer coefficient of transient dissolution for component $i$ from non-aqueous phase to aqueous phase $\left[\mathrm{T}^{-1}\right] ; C_{s a t_{i}}$ is the effective solubility of component $i$ in the multicomponent system $\left[\mathrm{ML}^{-3}\right] ; K_{m}$ is the sorption mass transfer rate parameter $\left[\mathrm{T}^{-1}\right]$, $S_{i}$ is the sorbed phase contaminant concentration, $\left[\mathrm{MM}^{-1}\right] ; V_{\max _{i}}$ is the maximum specific substrate utilization rate $\left[\mathrm{T}^{-1}\right] ; X_{a_{i}}$ is the aqueous phase biomass concentration $\left[\mathrm{ML}^{-3}\right]$ and $K_{s_{i}}$ is the half saturation constant $\left[\mathrm{ML}^{-3}\right]$.

\subsection{Dissolution kinetics for multicomponent system}

The dissolution term in Eq. (1) accounts for the influence of film resistance at the interface, NAPL composition and the effective solubility of each component defined according to Raoult's law. Since it is extremely difficult to capture the details of intrinsic mass transfer coefficient and the effective normalized interfacial area between NAPL and aqueous phase at the pore-scale using experiments or field investigations, the above two parameters are lumped together as a single entity called the 'lumped mass transfer coefficient $\left(K_{w n_{i}}\right)$ ', which represents the mean value over the Representative Elementary Volume (REV). Hence the term $K_{w n_{i}}$ accounts for the combined effects of fluid flow, interfacial area at the contact surface, and molecular diffusion of each contaminant as given by Eq. (2). It is generally represented in terms of dimensionless numbers that can be easily linked with the Darcy flux (Powers et al 1994; Garg \& Rixey 1999; Nambi \& Powers 2003; Chu et al 2007; Mobile et al 2012).

$$
K_{w n_{i}}=\frac{S h^{\prime} D_{m_{i}}}{d_{p}^{2}},
$$

where $S h^{\prime}$ is the modified Sherwood number [-] and $d_{p}$ is mean particle size of the porous medium [L].

The progression over years has been to modify the mass transfer correlation by including many parameters in order to closely represent actual phenomena of inter-phase mass transfer. It has been reported that most of the mass transfer occurs through molecular diffusion from the NAPL blob to the external flowing fluid through narrow pore throats, which is also influenced by the flow and NAPL properties (Miller et al 1990; Imhoff et al 1994; Mayer \& Miller 1996; Powers et al 1994; Nambi \& Powers 2003; Corapcioglu et al 2009; Burke 2012). By realizing that NAPL is actually providing the transferred mass, not the solid phase of the porous medium, the inclusion of volumetric residual NAPL saturation $\left(S_{n}\right)$ within the empirical correlation as an 
exponential term seems to modify the determination of characteristic length. In order to compare the mass transfer kinetics, suitable mass transfer correlation are selected according to the range of volumetric residual NAPL content $\left(\theta_{n}\right.$, which is defined as $\left.\theta_{n}=\varphi S_{n}\right)$ and Reynolds number $(R e)$, as mentioned in table 1.

The concept of residual saturation will serve as the identity for multicomponent scenario because all of them occupy the same pore volume represented by the residual saturation (Hamed et al 2000; Carroll \& Brusseau 2009, Mobile et al 2012). But the change in mole fraction influences the effective solubility as well as the remaining mass distribution in the NAPL phase, which in turn affect the dissolution mass transfer coefficient. It is observed that depending on the initial composition and spilled volume, methodology for estimating the effective solubility varies considerably (Borden \& Piwoni 1992; Feenstra 1997; Frind et al 1999; McCray \& Dugan 2002). In this regard, for the present scenario of known initial spilled volume and known composition, the following approach is used for estimating the change in NAPL saturation with the effect of change in mole fraction of each component.

Step 1: Initial volume of the NAPL mixture,

$$
V_{n}=\varphi V_{T} S_{n},
$$

where $\mathrm{V}_{T}$ is the total volume of domain $\left[\mathrm{L}^{3}\right] ; \mathrm{S}_{n}$ is the residual saturation of NAPL [-].

Step 2: Total moles of all components initially present,

$$
m_{t}=\frac{V_{n}}{\sum_{i=1}^{k} \frac{X_{n_{i} W_{i}}}{\rho_{n_{i}}}},
$$

where $k$ is the total number of components in the NAPL mixture [-]; $\mathrm{X}_{\mathrm{n}_{\mathrm{i}}}$ is the mole fraction of the component $i$; $W_{i}$ is the molecular weight of each component $i\left[\mathrm{Mmol}^{-1}\right]$ and $\rho_{\mathrm{n}_{\mathrm{i}}}$ is the liquid density of each component $i\left[\mathrm{ML}^{-3}\right]$.

Step 3: Initial mass of component ' $i$ ' in NAPL phase,

$$
M_{n_{i}}=X_{n_{i}} m_{t} W_{i}
$$

Step 4: Volume of pore water,

$$
V_{w}=\varphi V_{T}-V_{n}
$$

Step 5: The number of pore volume during each time step,

$$
N_{P V}=\frac{q \Delta t}{L \varphi S_{a}}
$$

Table 1. Selected mass transfer correlations for the study, with their range of parameters.

\begin{tabular}{lllll}
\hline Mass transfer correlation & Notation & Range of $\theta_{n}$ & Range of Re & Reference \\
\hline$S h^{\prime}=37.15 \operatorname{Re}^{0.61} S_{n}^{1.24}$ & MTC \# 1 & $0-0.168$ & $0.018-0.134$ & Nambi \& Powers (2003) \\
$S h^{\prime}=150 \operatorname{Re}^{0.87} \theta_{n}^{0.79}$ & MTC \# 2 & $0-0.04$ & $0.0012-0.021$ & Imhoff et al (1994) \\
$S h^{\prime}=6.25 \operatorname{Re}^{0.56} \theta_{n}^{0.64}$ & MTC \# 3 & $0-0.09$ & $0.013-0.05$ & Schaerlaekens et al (2000) \\
$S h^{\prime}=340 \operatorname{Re}^{0.71} \theta_{n}^{0.87}\left(\frac{x}{d_{50}}\right)^{-0.31}$ & MTC \# 4 & $0-0.04$ & $0.0012-0.021$ & Imhoff et al (1994) \\
\hline
\end{tabular}


where $L$ is the length of domain [L], $\Delta \mathrm{t}$ is the time step [T] and $S_{a}$ is volumetric water saturation $[-]$.

Step 6: Mass of component ' $i$ ' added to the aqueous phase (i.e., removed from non-aqueous phase) during each time step,

$$
M_{a_{i}}=C_{a_{i}} V_{w} N_{p v}
$$

Step 7: Mass of component ' $i$ ' remaining in NAPL phase,

$$
M_{n, \text { new }_{i}}=M_{n_{i}}-M_{a_{i}} \text {. }
$$

Step 8: Total number of moles in the NAPL phase for new time step,

$$
m_{t, \text { new }}=\sum_{i=1}^{k}\left(\frac{M_{n, \text { new }}}{W_{i}}\right) .
$$

Step 9: NAPL phase mole fraction for new time step,

$$
X_{\text {new } i}=\left(\frac{M_{n, \text { new }_{i}}}{m_{t, \text { new }_{i}} W_{i}}\right) .
$$

Step 10: New effective solubility,

$$
C_{\text {sat }_{i}}=C_{\text {sat }_{i}}^{0} X_{\text {new }_{i}}
$$

where $\mathrm{C}_{\mathrm{sat} i}^{\mathrm{o}}$ is the pure phase solubility of component $i$ in aqueous phase $\left[\mathrm{ML}^{-3}\right]$.

Step 11: Available NAPL volume for next time step,

$$
V_{n, \text { new }}=\sum_{i=1}^{k}\left(\frac{M_{n, n e w_{i}}}{\rho_{n_{i}}}\right) \text {. }
$$

Step 12: New NAPL saturation,

$$
S_{n, \text { new }}=\frac{V_{n, \text { new }}}{\varphi V_{T}} .
$$

Step 13: New volumetric NAPL content,

$$
\theta_{n, \text { new }}=\varphi S_{n} .
$$

Step 14: Dissolution mass transfer term is updated based on the new values of volumetric NAPL content $\theta_{n}$ as well as effective solubility $C_{\text {sat }_{i}}$.

Step 15: Value of NAPL volume $V_{n, \text { new }}$ from step 11 will be updated in step 1.

Step 16: Value of mole fraction, $X_{n e w_{i}}$ from step 9 will be updated in step 2.

Step 17: Value of NAPL mass remaining is checked for accuracy between step 7 and step 3 during every interval.

Generally, mass transfer of sorbing solutes may be affected by physical or chemical nonequilibrium resulting in delay in concentration breakthrough as well as tailing effect (Wang 2004; Couto \& Malta 2008). When the partitioning of dissolved contaminants between the solid and 
liquid phases is assumed to be rate-limited, the simulated concentration results in intermediate stages of retardation (Clement et al 1998). The value of the linear partitioning coefficient $\left(k_{d}\right)$ can be calculated from the fraction of organic carbon $\left(f_{o c}\right)$ and soil organic carbon partitioning coefficient $\left(k_{o c}\right)$ as given by $k_{d}=f_{o c} k_{o c}$. The sorbed phase concentration is obtained by the following mass balance equation (Clement et al 2004);

$$
\frac{\rho_{n}}{\varphi} \frac{\partial S_{i}}{\partial t}=K_{m}\left[(1-f) k_{d_{i}} C_{a_{i}}-S_{i}\right]
$$

In order to investigate the bioremediation potential of organic pollutants, aerobic biodegradation conditions in the saturated aquifer were studied in relation with sorption effects (Kim et al 2003; Couto \& Malta 2008; Yadav \& Hassanizadeh 2011). One of the primary reasons for enhanced dissolution is that it increases the concentration gradient at the interface, which increases the bio-availability of the compounds for the safe clean-up of the contaminated site (Bekins et al 1998; Clement et al 2004; Chu et al 2007; Diplock et al 2009). Based on the Monod kinetics for the mixed-order biodegradation reaction, concentration of the immobile biomass concentration was given by Bekins et al (1998):

$$
\frac{\partial X_{a_{i}}}{\partial t}=\frac{Y V_{\max _{i}} X_{a_{i}} C_{a_{i}}}{K_{s_{i}}+C_{a_{i}}}-K_{\text {decay }} X_{a_{i}},
$$

where $Y$ is the biomass yield coefficient [-] and $K_{\text {decay }}$ is the endogenous decay rate of biomass $\left[\mathrm{T}^{-1}\right]$.

The domain size for the problem under consideration is taken as $15 \mathrm{~cm}$ length and having a diameter of $2.5 \mathrm{~cm}$, typically representing a laboratory scale column uniformly filled with fine sand. The typical toxic compounds in petroleum such as benzene, toluene, ethylbenzene and xylene are selected as the target compounds, which are present initially at a specific mole fraction contributing to the initial residual saturation and distributed uniformly throughout the domain.

\subsection{Numerical solution}

The system of coupled partial differential equations is discretized in temporal and spatial coordinates using finite difference approximations to make it in algebraic form. The advection term is modelled as fully implicit and dispersion term as semi-implicit (Crank-Nicholson). The resulting set of tri-diagonal matrix is solved using Thomas algorithm in FORTRAN environment. The initial and boundary conditions for the numerical scheme are given in table 2 . The top boundary is Cauchy-type, because the NAPL source is distributed within the domain as residual saturation $\left(S_{n}\right)$, and the net advective and dispersive flux at the boundary is due to constant inflow characterized by Darcy velocity and dispersivity as given in table 3 . However, the variation in the overall dispersion is taken into account by incorporating the molecular diffusion of NAPL as well as change in pore velocity $(v)$ as a function of $S_{n}$.

The dissolution model for the contaminant coupled with rate-limited sorption as well as biodegradation governed by Monod kinetics is given by Eq. (1), whereas sorbed phase concentration and biomass concentration can be estimated sequentially from Eqs. (16) and (17), respectively. The rate-limited dissolution model is solved by selecting suitable mass transfer correlation provided in table 1 and substituting Eqs. (2) in (1). The details of the parameters used for the numerical study are given in table 3 . The values of important physical and chemical properties of the compounds are given in table 4. 
Table 2. Initial and boundary conditions for the selected numerical scheme.

\begin{tabular}{ll}
\hline Initial conditions & Boundary conditions \\
\hline$C_{a_{i}}(x, t=0)=0$ & $v C_{a_{i}}-D \frac{\left(C_{a_{i+1}}-C_{a_{i}}\right)}{\Delta x}=0$ \\
$X_{i}(x, t=0)=2$ & $\left.\frac{\partial C_{a_{i}}}{\partial x}\right|_{(x=L, t)}=0$ \\
$S_{i}(x, t=0)=0$ & \\
\hline
\end{tabular}

Table 3. Dataset of parameters for the numerical model.

\begin{tabular}{llll}
\hline Parameter & Notation & Value & Reference \\
\hline Length of column $(\mathrm{m})$ & $\mathrm{L}$ & 0.15 & Assumed value \\
Diameter of column $(\mathrm{m})$ & $\mathrm{d}$ & 0.022 & Assumed value \\
Soil porosity (-) & $\mathrm{n}$ & 0.40 & Couto \& Malta (2008) \\
Longitudinal dispersivity $(\mathrm{m})$ & $\alpha$ & 0.001 & Couto \& Malta (2008) \\
Soil bulk density $\left(10^{6} \mathrm{~g} / \mathrm{m}^{3}\right)$ & $\rho_{b}$ & 1.60 & Clement et al (1998) \\
Fraction of organic carbon $(-)$ & $\mathrm{f}_{o c}$ & 0.01 & Essaid et al (2003) \\
pore velocity (m/day) & $\mathrm{v}$ & 1.0 & Assumed value \\
Initial NAPL saturation $(-)$ & $\mathrm{S}_{n}$ & $0.03-0.3$ & Assumed value \\
Medium grain size $(\mathrm{m})$ & $\mathrm{d}_{p}$ & 0.00032 & Couto \& Malta (2008) \\
Time step (day) & $\Delta \mathrm{t}$ & 0.005 & Calculated value \\
Length step $(\mathrm{m})$ & $\Delta \mathrm{x}$ & 0.01 & Calculated value \\
\hline
\end{tabular}

Table 4. Physical and chemical properties of benzene (B), toluene (T), ethylbenzene (E) and xylene (X).

\begin{tabular}{|c|c|c|c|c|c|}
\hline Parameter & B & $\mathrm{T}$ & $\mathrm{E}$ & $X$ & Reference \\
\hline Molecular weight (g mol) & 78 & 92 & 106 & 106 & ASTM 1995 \\
\hline Pure phase density $\left(10^{6} \mathrm{~g} / \mathrm{m}^{3}\right)$ & 0.88 & 0.87 & 0.86 & 0.87 & ASTM 1995 \\
\hline Pure phase solubility (mg/L) & 1750 & 535 & 152 & 198 & ASTM 1995 \\
\hline $\begin{array}{l}\text { Molecular diffusion coefficient, } \\
\mathrm{D}_{m}\left(10^{-5} \mathrm{~m}^{2} / \text { day }\right)\end{array}$ & 1.10 & 0.95 & 0.85 & 0.85 & ASTM 1995 \\
\hline $\begin{array}{l}\text { Soil organic carbon partitioning } \\
\text { coefficient, } \mathrm{k}_{o c}(\log \mathrm{L} / \mathrm{kg})\end{array}$ & 1.58 & 2.13 & 1.98 & 2.38 & Lovanh et al 2000 \\
\hline $\begin{array}{l}\text { Sorption mass transfer } \\
\text { coefficient, } K_{m}\left(\text { day }^{-1}\right)\end{array}$ & 0.015 & 0.015 & 0.015 & 0.015 & Lovanh et al 2000 \\
\hline Effective retardation factor, Ret (-) & 1.15 & 1.54 & 1.38 & 1.96 & Calculated value \\
\hline $\begin{array}{l}\text { Maximum specific substrate } \\
\text { utilization rate, } V_{\max }\left(\text { day }^{-1}\right)\end{array}$ & 1.2 & 1.9 & 0.9 & 0.9 & $\begin{array}{l}\text { Maliyekkal et al 2004; } \\
\text { Alvarez } 1991\end{array}$ \\
\hline Half-saturation constant, $\mathrm{K}_{s}(\mathrm{mg} / \mathrm{L})$ & 80 & 100 & 50 & 50 & $\begin{array}{l}\text { Maliyekkal } \text { et al 2004; } \\
\text { Bielefeldt \& Stensel, } 1999\end{array}$ \\
\hline $\begin{array}{l}\text { Endogenous decay } \\
\text { constant, } \mathrm{K}_{\text {decay }}\left(\text { day }^{-1}\right)\end{array}$ & 0.02 & 0.02 & 0.02 & 0.02 & Couto \& Malta 2008 \\
\hline Yield coefficient, Y (-) & 0.3 & 0.3 & 0.2 & 0.2 & $\begin{array}{l}\text { Priya \& Philip 2013; } \\
\text { Couto \& Malta } 2008\end{array}$ \\
\hline
\end{tabular}




\section{Results and discussions}

The results of numerical simulation studies are important to assess the versatility of the numerical techniques, the significance of the prevailing assumptions and the selection of dissolution mass transfer correlation. The present model is checked for its numerical stability and the contaminant mass balance is confirmed within close proximity. The present multicomponent dissolution model is tested against the experimental data given by Borden \& Piwoni (1992) for the aqueous concentrations of benzene, toluene and xylene in order to select suitable mass transfer correlation for a similar experimental condition.

Figure 1 provides the comparison of numerically simulated concentrations of benzene, toluene and xylene present as a mixture using various mass transfer correlations in comparison with the experimental data from Borden \& Piwoni (1992). Even though these compounds resemble in many physico-chemical characteristics, their relative solubility and structural properties differ significantly to constitute non-ideal nature. Hence, in most cases, the simulation of realistic breakthrough profile of these compounds is relatively tough to appreciate in terms of peak concentration and extended tailing (Johnson et al 2003). It is observed from figure 1 that the correlation MTC\#1 is in close agreement with the initial phase of dissolution as well as capturing the peak concentration of benzene and toluene corresponding to their effective solubility; however the peak value of xylene is slightly lower than the observed value of effective solubility.

The mass balance estimates revealed that error is minimal with the use of MTC\#1, which is also clear from figure 1. It is observed that the peak value pertaining to the equilibrium concentration of xylene has taken a relatively longer duration (nearly 2 days) in comparison with that of toluene (nearly 1 day) and benzene ( 0.5 day). Conversely, the present model is able to capture the tailing part of dissolution profile more closely for lesser soluble compound (xylene) than for more soluble compound (benzene). It is also observed from figure 1 that other mass transfer correlations are not able to closely simulate this kinetic nature of dissolution, especially when the conditions are conducive for equilibrium mass transfer (for highly soluble compounds), which is attributed to the range of coefficients used in these correlations. During the initial phase, the dissolution mass transfer rate is very high due to the high concentration gradient, and as dissolution progresses, the mole fraction decreases in the mixture, which in turn decreases its effective solubility. While studying the behaviour of these correlations on the extent of simulation time, it is observed that occurrence of high peak concentration is inversely proportional to the extent of tailing because of the decrease in effective solubility facilitated by the change in mole fraction.

\subsection{Simulation results for equimolar mixture of BTEX at residual saturation}

The model is run for the selected problem domain (table 3) with equimolar mixture of benzene, toluene, ethylbenzene and xylene (BTEX) using the four different mass transfer correlations (table 2) and the results are presented in figure 2. The domain conditions resemble typical lab scale experimental set-up with initial residual saturation of 25 percent and Darcy velocity of $0.5 \mathrm{~m} /$ day. It is clearly observed from figure 2 that concentration elution follows chromatographic nature with variable breadth of the peak concentration in accordance with their effective solubility. The apparent tailing in the concentration of low soluble fraction in the mixture is due to the declining solubility rather than mass transfer kinetics as reported in previous studies (Frind et al 1999; Johnson et al 2003).

One distinct observation is that the peak concentration of toluene occurs at the same time when benzene concentration is almost zero. Similarly, the peaks of ethylbenzene and xylene occur at 

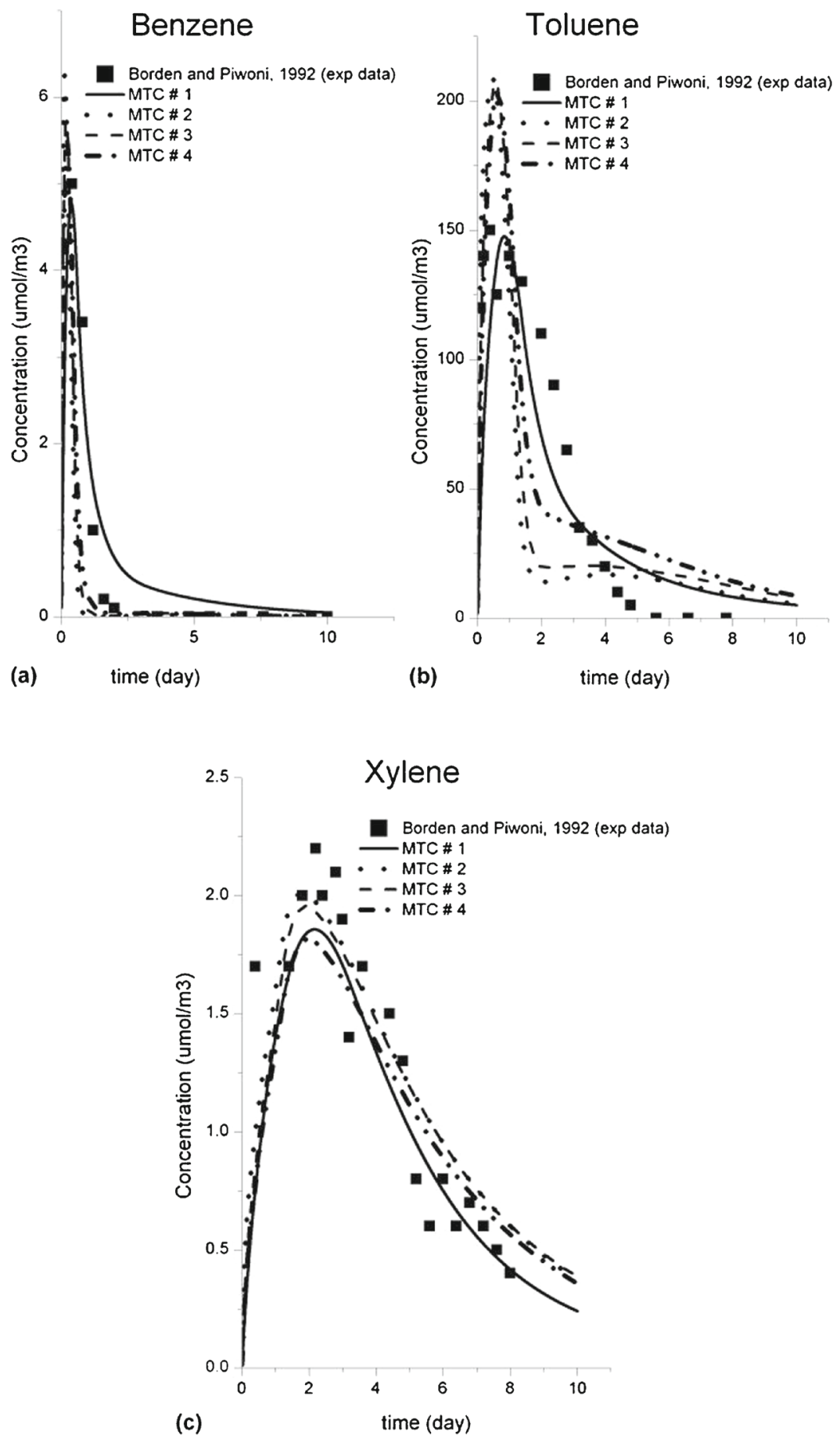

Figure 1. Validation of the multicomponent dissolution model using different mass transfer correlations (MTC) for aqueous concentrations of Benzene, Toluene and Xylene in comparison with Borden \& Piwoni (1992) [Refer table 1 for details]. 

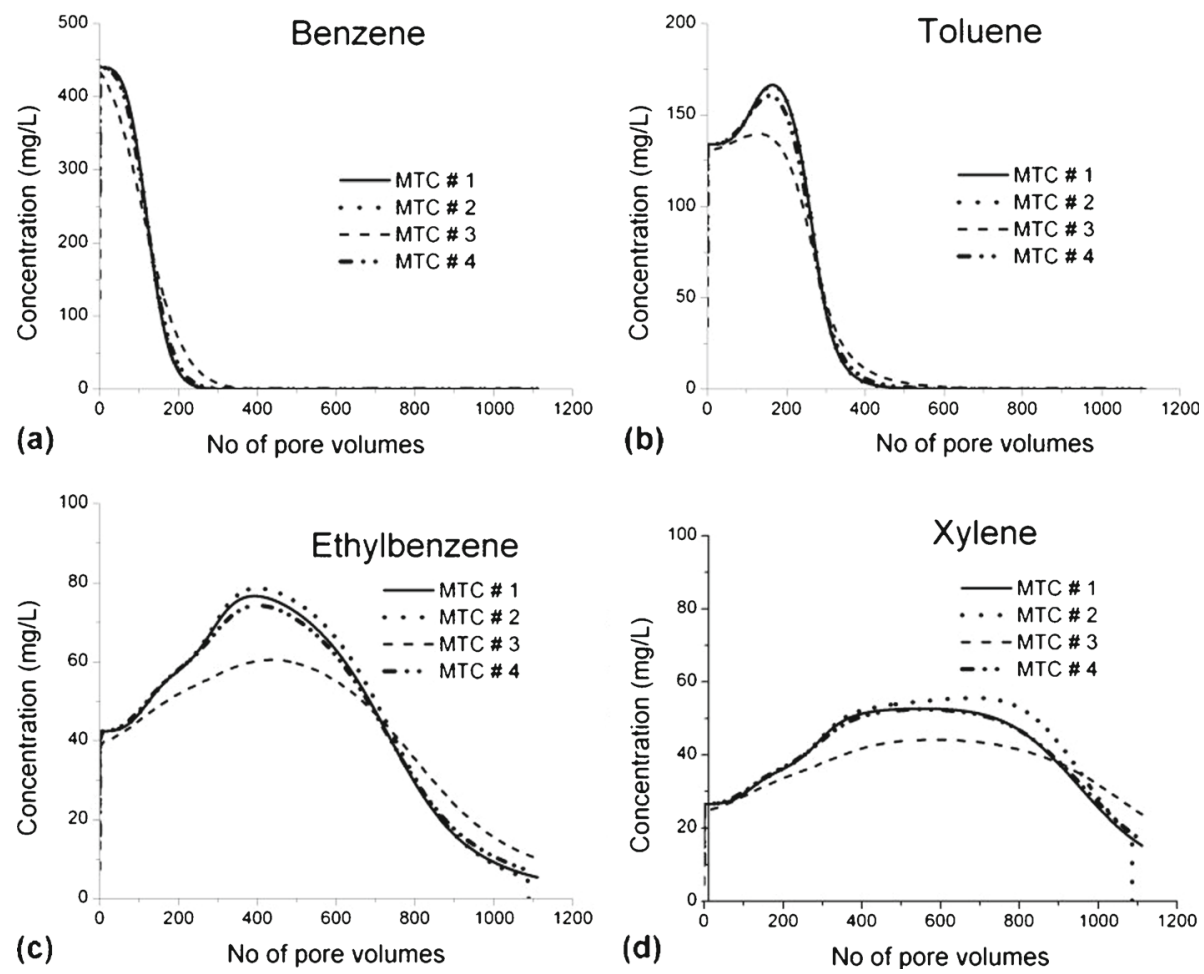

Figure 2. Temporal distribution of (a) Benzene, (b) Toluene, (c) Ethylbenzene and (d) Xylene for different dissolution mass transfer correlations [Refer table 1 for details].

the time when toluene has almost disappeared. It is observed from figure 2 that time required for the arrival of peak concentration for individual components is inversely proportional to their effective solubility and hence the total time required for complete source removal is limited by the solubility of the lowest soluble compounds (ethylbenzene and xylene) and their mole fraction in the mixture.

The mean error obtained during the mass balance calculation for the simulation of single compound as well as multicomponent system for different mass transfer correlations is provided in table 5. It is observed that the difference between initial mass of contaminant and the total eluted mass as estimated by the numerical model is more precise in case of single compound system. However, for the multicomponent model, estimated error is similar for all correlations except for MTC\#3 which is influenced by the low coefficient values of the model parameters (Schaerlaekens et al 2000). It is reported that the correlation developed by Nambi \& Powers (2003) is suitable for handling heterogeneity of the porous media and for higher ranges of

Table 5. Comparison of mass balance error between single and multicomponent models.

\begin{tabular}{lcccc}
\hline & \multicolumn{3}{c}{ Error (\%) calculation for various mass transfer correlations } \\
\cline { 2 - 5 } & MTC\#1 & MTC\#2 & MTC\#3 & MTC\#4 \\
\hline Single component & 0.0003 & 0.0205 & 0.0651 & 0.1268 \\
Multicomponent & 1.5021 & 1.4977 & 2.5900 & 1.4922 \\
\hline
\end{tabular}


NAPL saturation and Reynolds number (Grant \& Gerhard 2004; Prakash \& Nambi 2012). Since majority of mass transfer correlations yielded similar profiles as Nambi \& Powers (2003) with minimum relative error, it is chosen for further simulations.

The coupled effect of kinetic sorption and biodegradation with rate limited dissolution on the aqueous concentration of benzene, toluene, ethylbenzene and xylene for the selected domain were also studied. It is observed from figure $3 \mathrm{a}$ that there is no apparent distinction with the effect of coupled reactions in the concentration of benzene due to the high effective solubility (440 $\mathrm{mg} / \mathrm{L}$ ), resulting in faster reduction within first 250 pore volumes. From figure $3 \mathrm{~b}$, the toluene concentration showed a peak value of $170 \mathrm{mg} / \mathrm{L}$ at 200 pore volumes, which occurred when benzene concentration has significantly receded. The effect of coupled reactions is clearly seen during the descending limbs of the profile, especially for lesser soluble compounds. At earlier times, the degradation has resulted in increasing concentration gradient resulting in higher mass transfer rates and higher aqueous concentrations. The same phenomena has been the driving force for drop in concentration at later times under rate limited dissolution conditions resulting in reduction in total pore volumes for fast removal.

It is observed that as the higher soluble fractions have flushed out, the mole fraction of lesser soluble fractions increase; further increase their effective solubility, which is progressive towards higher pore volumes. At this stage, these compounds partition to the aqueous phase irrespective of low mass transfer rate, resulting in significant reduction of aqueous concentration due to the
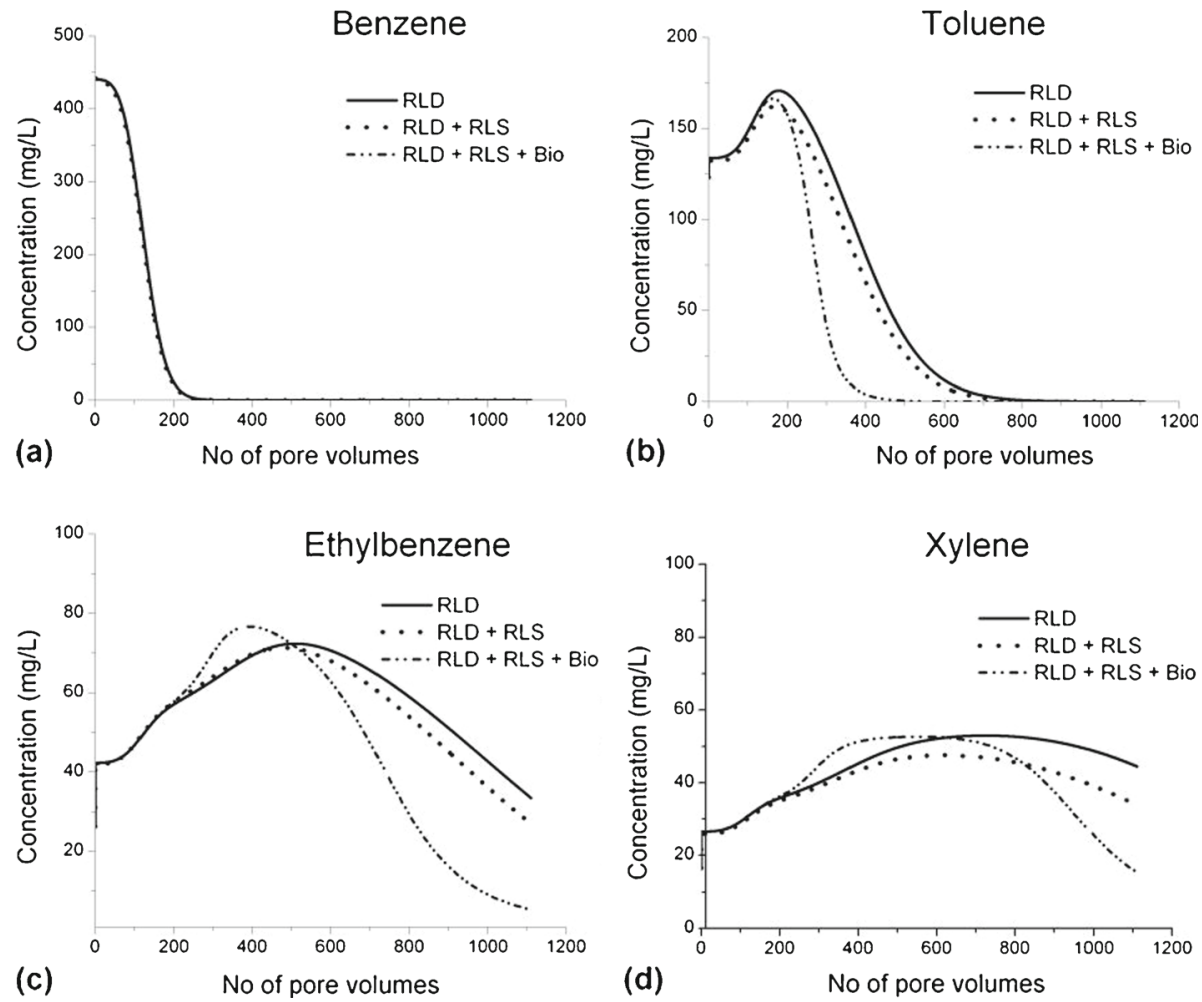

Figure 3. Temporal distribution of (a) Benzene, (b) Toluene, (c) Ethylbenzene and (d) Xylene under various coupled reaction scenarios. [RLD $=$ Rate limited dissolution, $\mathrm{RLS}=$ Rate limited sorption, Bio $=$ Biodegradation]. 
coupled biodegradation. However, it is interesting to note that complete removal of lower solubility compounds is not achieved within the simulation period of 1100 pore volumes, although there is a significant reduction in concentrations due to biodegradation and sorption when compared to concentrations when dissolution alone is present.

\subsection{Comparison of mass transfer models for single and multi-component NAPL}

The simulation results are compared between single and multi-component system for the same mass of compounds, as established by the residual saturation. When specific composition of the mixture is not known, the concept of residual saturation will serve as the sole representative of contaminants. However, for the multi-component mixture, apart from the initial mole fraction and effective solubility for less soluble compounds, the combined effect of sorption and biodegradation will determine the extent of contamination. Hence it is important to recognize the dissolution pattern for the sparingly soluble compounds when they are present as the sole constituent as well as when they come in a mixture.

As it is clear from figure 4, the kinetic nature of single compound dissolution is increasing with decreasing solubility, even though the peak concentration is always lower than aqueous solubility value. However, when they are present in a mixture, the peak value corresponds to the effective solubility of individual compounds at a particular mole fraction. This is clear from figure 4a that benzene concentration in the mixture reached its effective solubility of $440 \mathrm{mg} / \mathrm{L}$, whereas when
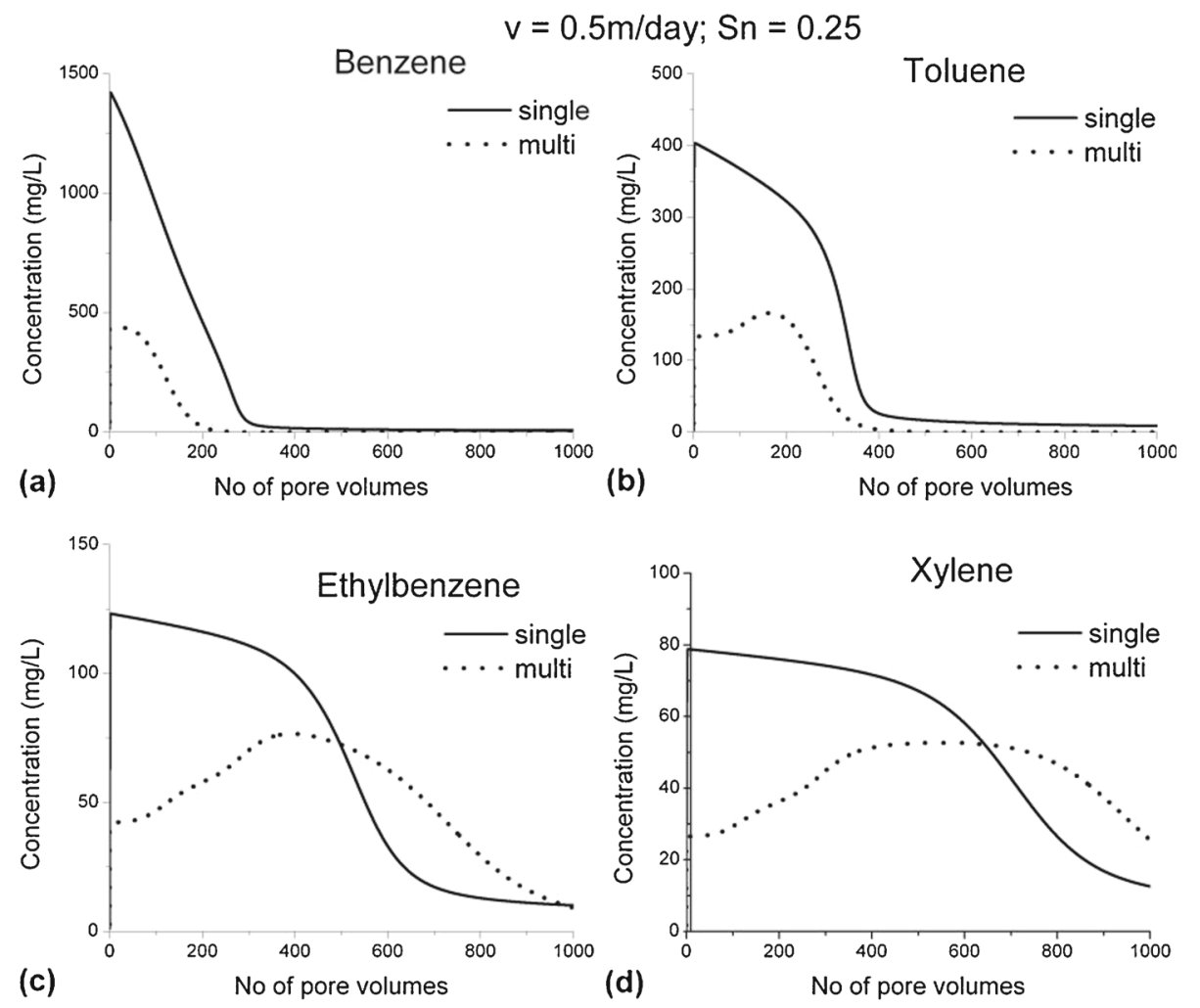

Figure 4. Comparison of concentration profiles of (a) Benzene, (b) Toluene, (c) Ethylbenzene and (d) Xylene when present in single and multicomponent system. 
it is present alone the peak concentration is $1450 \mathrm{mg} / \mathrm{L}$ which is near to its solubility value. Similarly, the aqueous concentration profile for toluene as a single compound is always higher than for the multicomponent system. Since toluene reaches peak value after significant flushing of benzene, the apparent increase in the mole fraction of toluene results in higher effective solubility than observed during the initial phase of dissolution. However, for ethylbenzene and xylene, the effective solubility values cross over the single compound solubility values towards higher pore volumes indicating the fact that the apparent increase in the mole fraction after 400 pore volumes result in high effective solubility. The pore volume requirement for the more soluble fractions is less in the mixture compared to their single state, whereas more hydrophobic compounds exhibit comparatively higher mass transfer limitation especially when they are present in the mixture.

\subsection{Sensitivity analysis of single and multi-component models}

It is generally observed that at high flow rate lesser contact time is available, and at lower saturation dissolution occurs over smaller interfacial area; hence both conditions are conducive for mass transfer limitation. Similarly, higher residual NAPL saturation and lower flow rates result in higher aqueous phase concentration close to equilibrium and more time for complete mass removal. Hence it is important to evaluate the influence of initial source strength and mean fluid velocity on the dissolution mass transfer in order to understand the extent of mass transfer limitation.
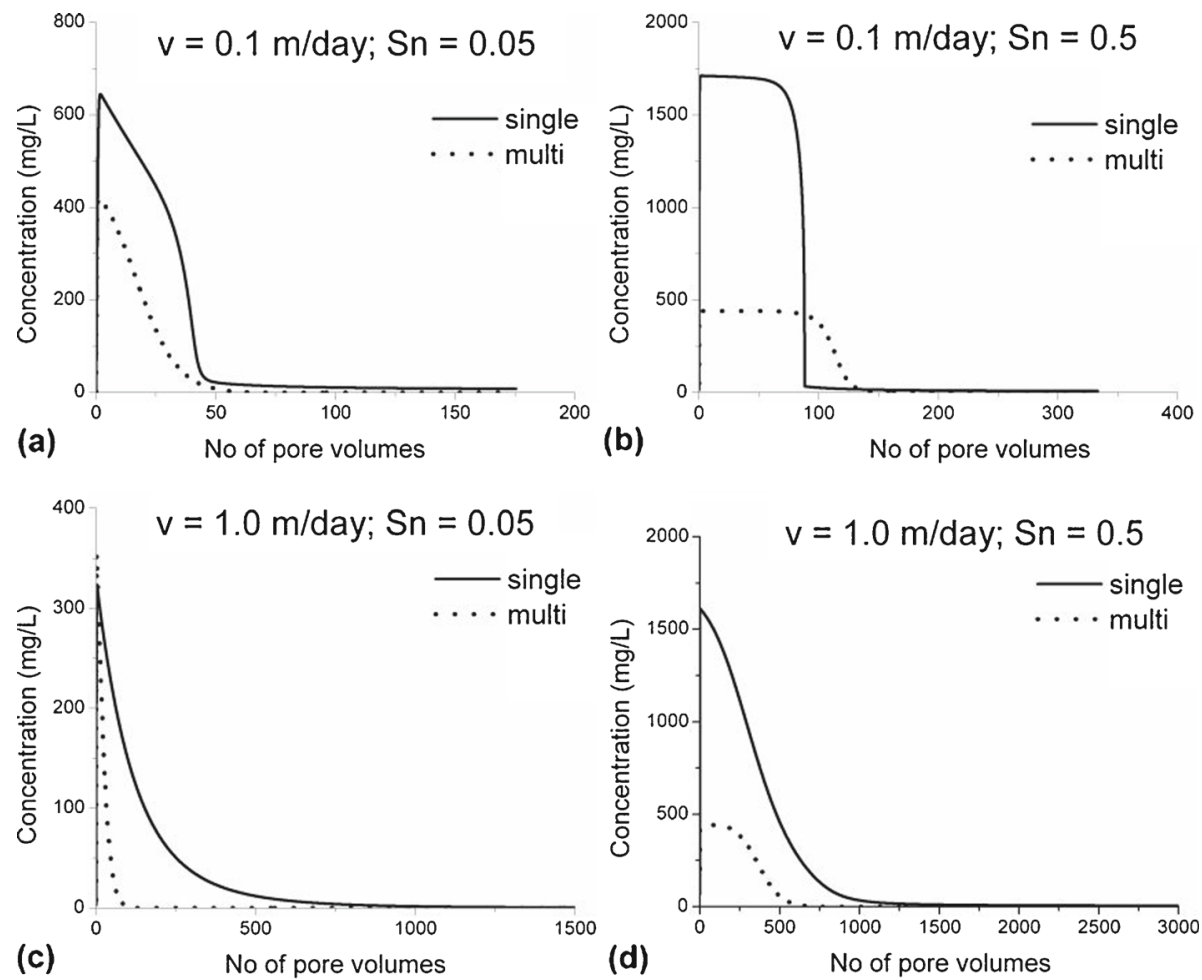

Figure 5. Comparison of benzene concentration in a single and multicomponent system for different combinations of $\mathrm{v}$ and $\mathrm{S}_{n}$. 
It is observed from figure 5 that for single compound system, increasing velocity by an order of magnitude results in increase in pore volume requirement by one order due to the mass transfer limitation at higher velocity conditions. Also the increase in NAPL saturation by an order of magnitude results in doubling the pore volume requirement. However, for multicomponent system, the increase in pore volume requirement corresponding to increase in NAPL saturation is about 2.5 times and 5 times for velocity values of 0.1 and $1.0 \mathrm{~m} /$ day, respectively. Similarly, an order of magnitude increase in velocity results in increase of pore volume requirement by 2 times and 4 times corresponding to NAPL saturation values of 5 and 50 percent, respectively. Benzene concentration reached its maximum solubility only when the velocity is low and NAPL saturation is high resulting in more contact time, which is in agreement with the equilibrium dissolution criteria (Seagren et al 1999; Johnson et al 2003). Also under low NAPL saturation and low velocity conditions, the difference in the behaviour of single and multicomponent NAPL dissolution is significantly less.

The shape of the dissolution profile for toluene is also studied under similar conditions as shown in figure 6, showing the influence of residual NAPL saturation and mean fluid velocity. It is observed that when the $S_{n}$ is high, toluene exhibits tendency towards equilibrium dissolution which is more significant at low velocity (figures $6 \mathrm{~b}$ and d), resulting in shock like high concentration during the initial phase. When toluene is present in the mixture, it resulted in lower effective solubility and low pore volume requirement. But the peak concentration in figure $6 \mathrm{c}$ is higher because of the high flow rate and increased mole fraction of toluene after the elution of
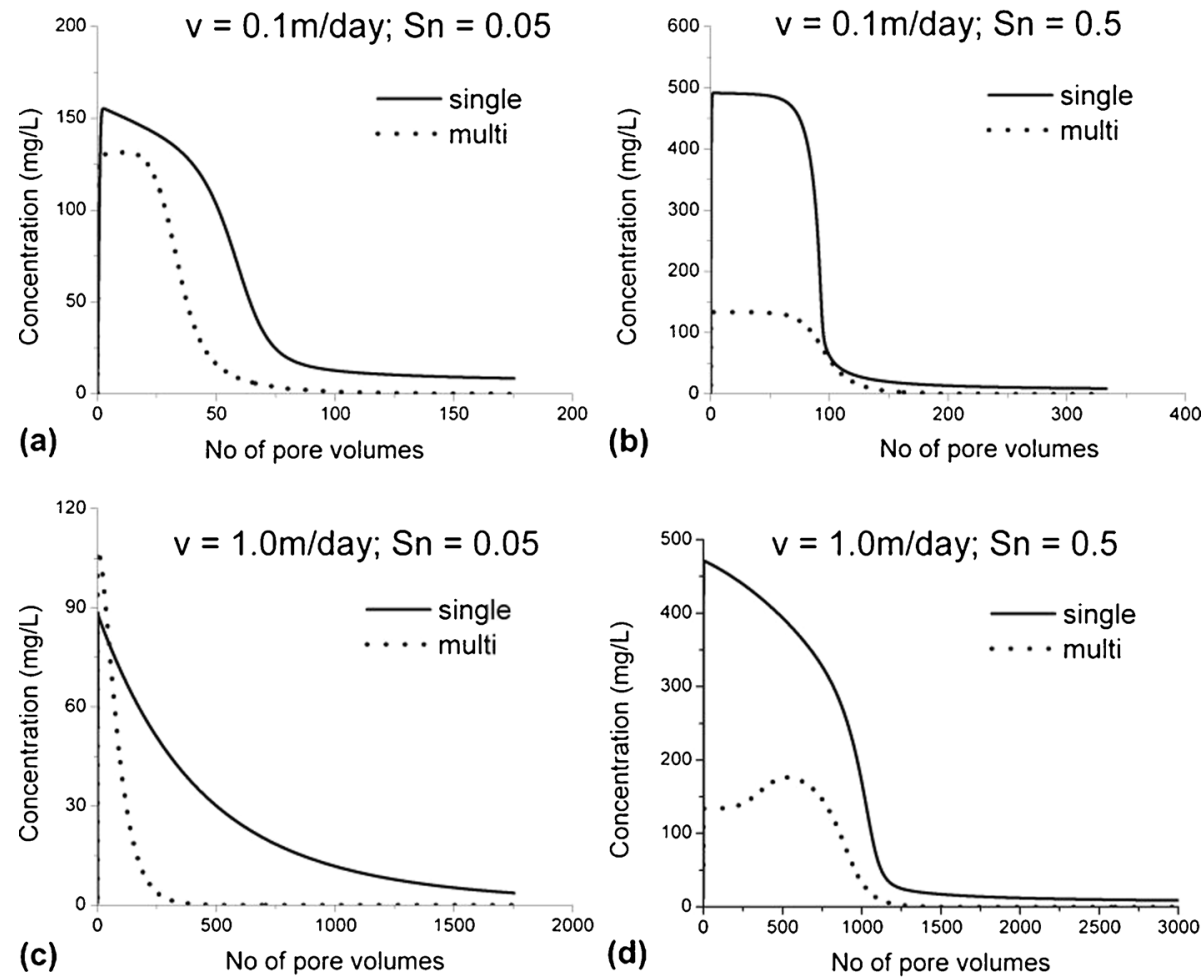

Figure 6. Comparison of toluene concentration in a single and multicomponent system for different combinations of $\mathrm{v}$ and $\mathrm{S}_{n}$. 
benzene from the system. For single compound model at low saturation conditions (figures 6a and c), the peak concentrations are lower than the expected solubility values irrespective of velocity, indicating the prevailing kinetic nature of dissolution. As observed from figure $6 \mathrm{c}$, high velocity and low $S_{n}$ is conducive for exponential decrease in concentration profile, but when $S_{n}$ is very high (figure 6d), it results in high peak value and subsequently sharp declining limb, unlike the case of benzene.

The concentration profile of ethylbenzene is compared in figure 7 for different values of velocity and residual saturation to understand the extent of mass transfer for the less soluble fraction under rate limiting conditions. The kinetic nature of dissolution is prominent during the initial pore volumes is mainly due to low contact time, but at higher pore volumes the effect of velocity is more significant even though $S_{n}$ has reduced considerably, resulting in reduced available interfacial area (figure 7c). It is to be noted from figures $7 \mathrm{a}$ and $\mathrm{c}$ that both single and multicomponent system behave closely near peak values, but multicomponent model predicts more sharp decrease towards larger pore volumes due to the increase in effective solubility resulting from increased mole fraction.

Figures $7 \mathrm{~b}$ and $\mathrm{d}$ show that the peak concentrations predicted by multicomponent model is much lower and delayed as compared to single compound model. This is particularly important to understand the dissolution behaviour at high $S_{n}$ values when majority of mole fraction is composed of low soluble compounds. It is also observed that high velocity conditions are conducive for higher dispersive effects for the concentration profile after achieving the peak concentration.
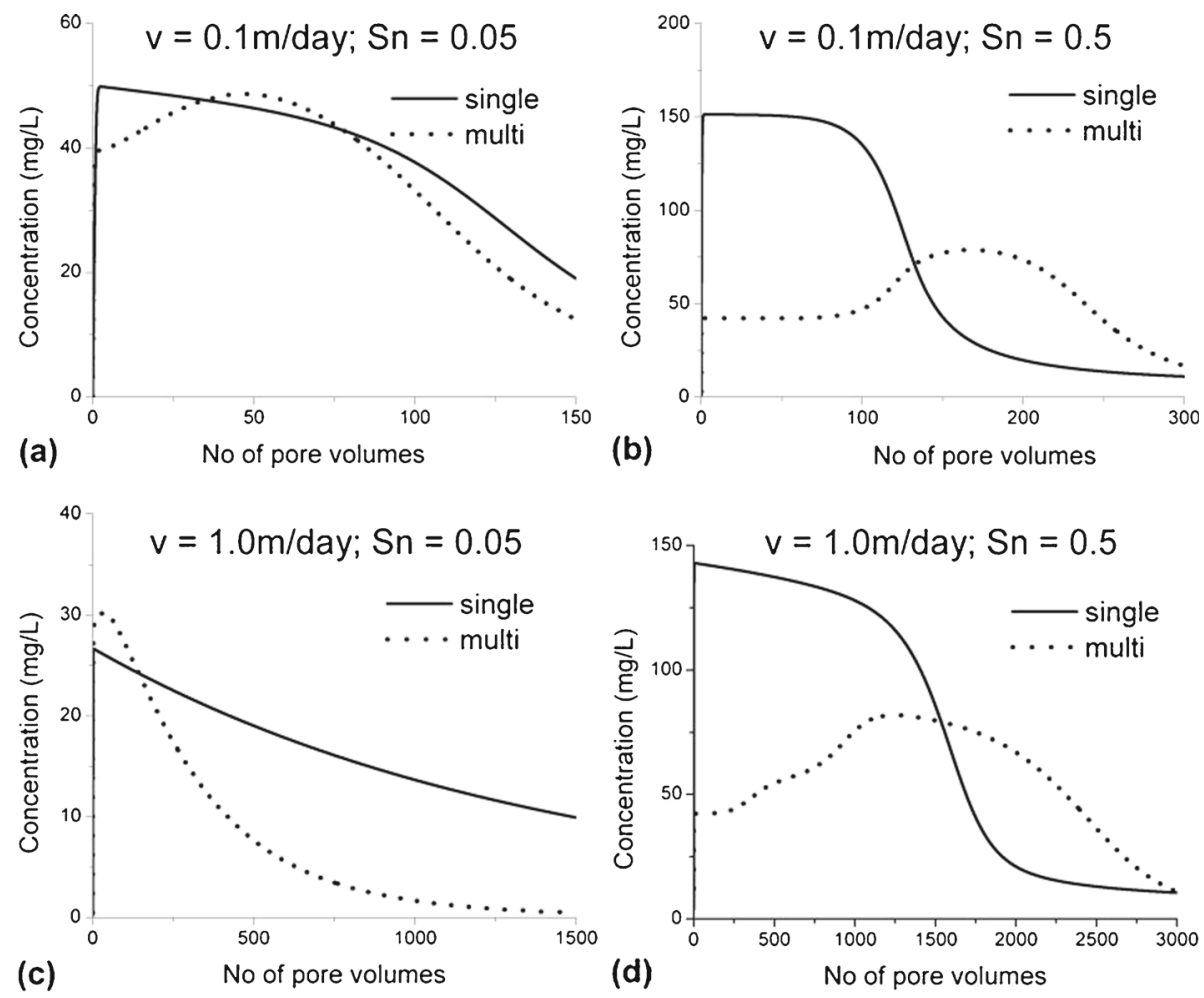

Figure 7. Comparison of ethylbenzene concentration in a single and multicomponent system for different combinations of $\mathrm{v}$ and $\mathrm{S}_{n}$. 
The concentration profile of the least soluble compound in the mixture, xylene is compared for different conditions of velocity and $S_{n}$ as given in figure 8 to understand dissolution behaviour. It is observed from figure 8 that when present alone, there is considerable reduction in xylene concentration only after prolonged flushing and it is not much effective at high flushing velocity. However, when it is present in the mixture, it reaches the peak value with much delay compared to other compounds (figures $8 \mathrm{~b}$ and $\mathrm{d}$ ), and thereafter the NAPL saturation is solely dependent on xylene concentration. Because of the low solubility and hence low mass transfer rate, practically it is not possible to remove xylene completely from the system under the given conditions. It can be concluded from figure 8 that when the initial NAPL saturation is high, the time required for complete removal of lesser soluble components will be extremely high as compared to the more soluble components in the mixture. Also, since the residual NAPL saturation is not completely removed within the simulated time period, it is to be considered as a continuing source of contamination, even though significant amount of higher soluble fractions have been removed.

Figure 9 provides the quantitative estimation of dissolution mass transfer rate coefficient of benzene for the above selected conditions in order to highlight the coupled effect of transient and nonlinear reactions. At high residual saturation and low velocity, the condition resembles equilibrium mass transfer for dissolution. Since the mass transfer rate coefficient $\left(K_{w n i}\right)$ is exponentially dependent on the residual NAPL saturation $\left(S_{n}\right)$, it is expected to have higher influence compared to the increase in velocity (table 1 ). This is expected to be a favourable condition for efficient mass transfer, and is in accordance with concentration profiles (Figures 5, 6, 7 and 8).
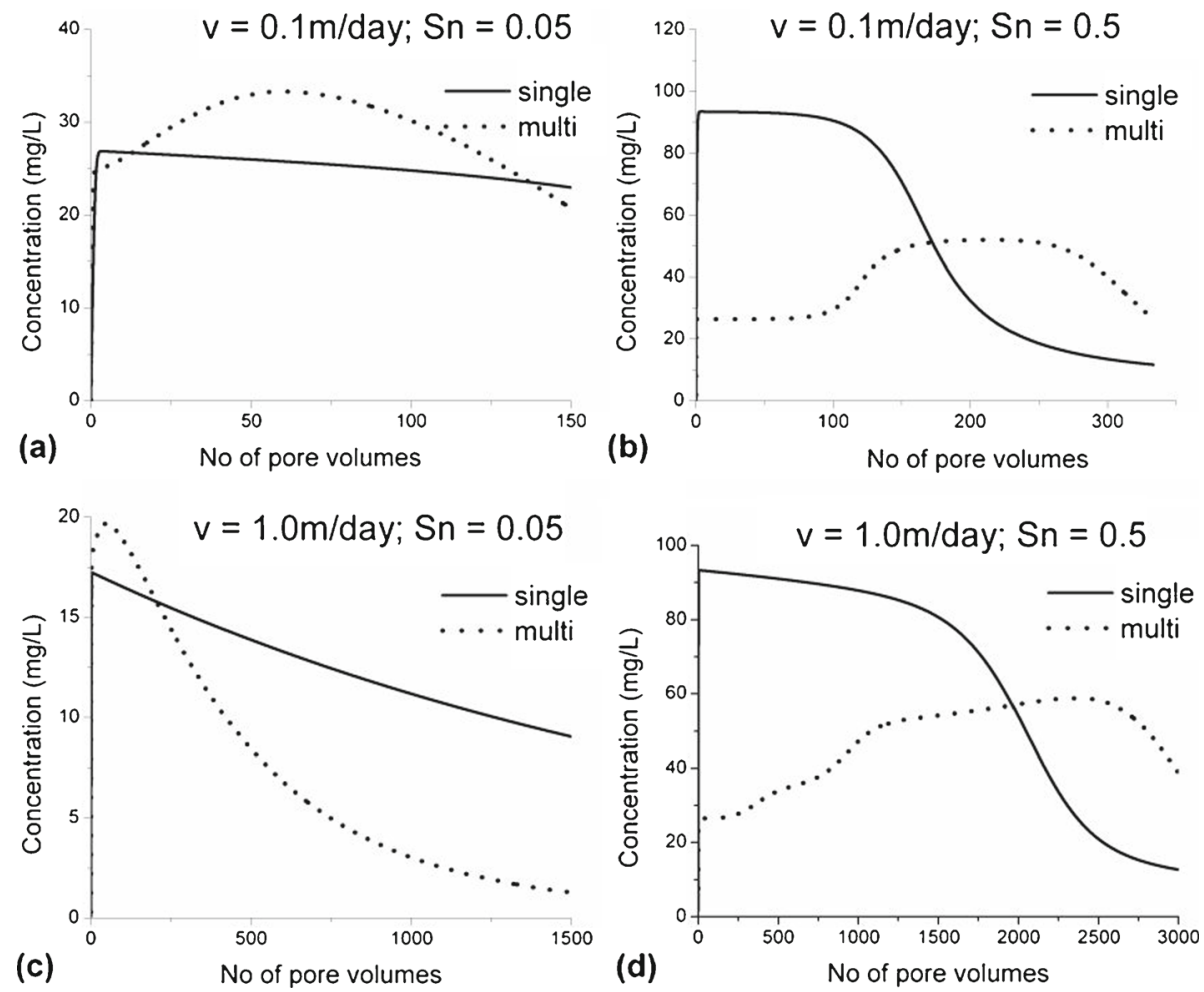

Figure 8. Comparison of xylene concentration in a single and multicomponent system for different combinations of $\mathrm{v}$ and $\mathrm{S}_{n}$. 

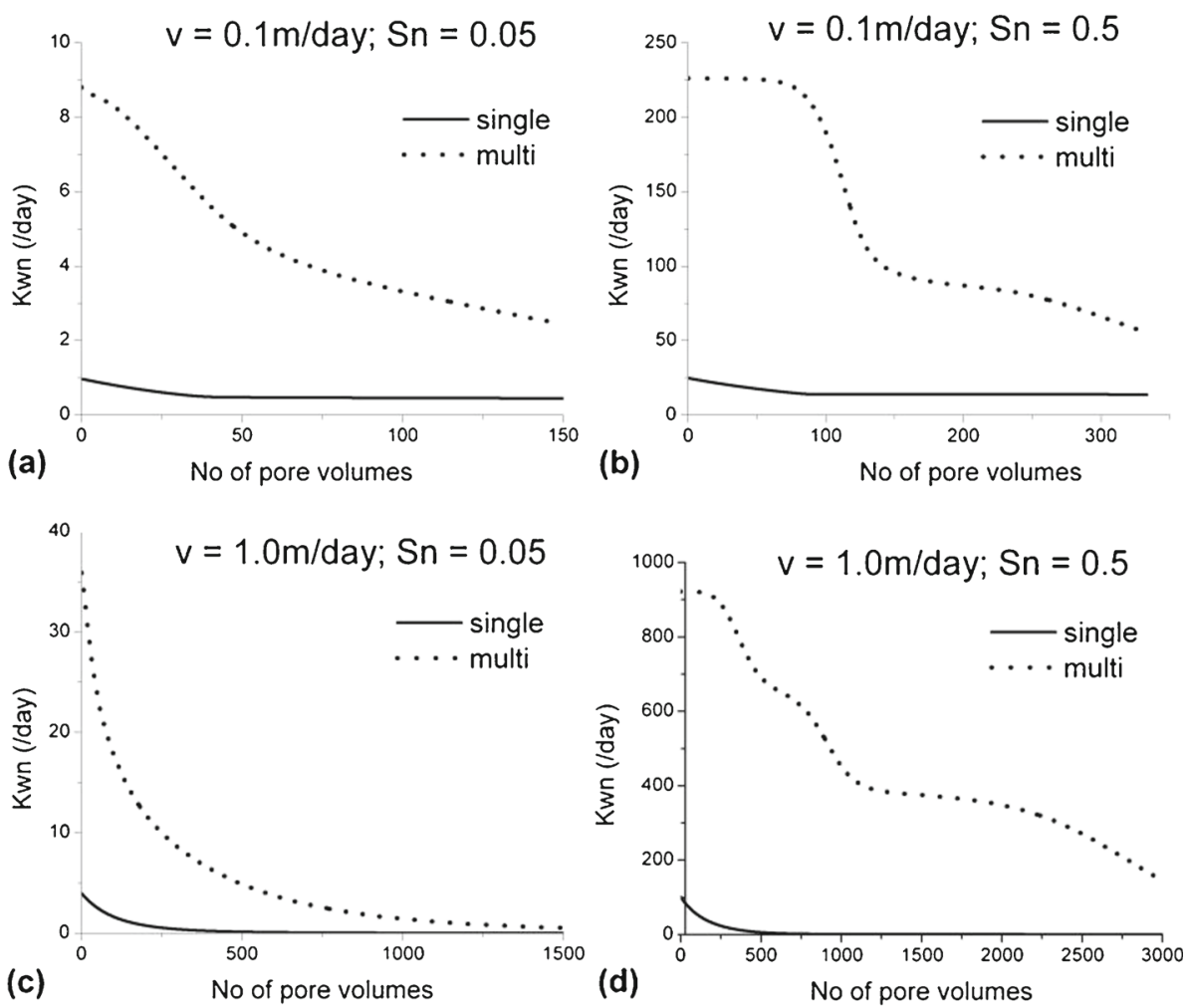

Figure 9. Variation of dissolution mass transfer rate coefficient $\left(\mathrm{K}_{w n}\right)$ for benzene under different conditions of velocity and $\mathrm{S}_{n}$.

In the case of multi-component dissolution the mass transfer rate of individual component depends more on the evolution of the components of $\mathrm{Sn}$ rather than $S_{n}$ as a whole. This is controlled by the preferential partitioning of the more soluble components in the mixture and the mole fractions of the same. The evolution of mole fraction is also found to be nonlinear, which is increasing for the lesser soluble compounds, when the soluble compounds dissolve. Hence, in accordance with the removal of more soluble fraction, the mass transfer rate is high initially and decreases until considerable mass has been removed. It is observed from figures $9 \mathrm{a}$ and $\mathrm{c}$ that the decrease in mass transfer rate is progressive but steeper for high velocity. Also, figures $9 \mathrm{~b}$ and d indicate that mass transfer rate is very high for large values of $S_{n}$, and its reduction is similar to the reduction in concentration up to 150 pore volume and 1000 pore volumes, respectively. Thereafter the dissolution rate is slow but continuous due to the presence of $S_{n}$ in the system. The dissolution mass transfer coefficient in the multicomponent system is found to be highly nonlinear and extending with changing slope, unlike the exponential reduction in case of single compound system. Hence understanding the variation of dissolution rate coefficient is necessary to explain the mass transfer limiting conditions at higher pore volumes, especially for more soluble compounds. It is observed from the multicomponent model that the reduction of $S_{n}$ is highly favoured by high velocity conditions resulting in complete removal of compound from the system. The present model is able to predict the long tailing portion for these conditions with minimum mass balance error, indicating that $S_{n}$ value is more dependent on the mole fraction 
of the least soluble component. Considering residual NAPL saturation as the true indication for contaminant source strength, it is evident from this study that complete source zone clean up is possible by high velocity flushing, if no other solubility enhancement methods are utilized.

\section{Summary and conclusion}

Present study discusses the applicability of a comprehensive numerical model for characterizing the possible mass transfer limitation when a multicomponent NAPL is undergoing simultaneous dissolution, sorption and biodegradation. The predictions were validated with existing data in literature. The predictions made using the correlation developed by Nambi \& Powers (2003) are in close agreement with the initial phase of dissolution as well as capturing the peak concentration of benzene and toluene corresponding to their effective solubility. The present model is able to predict the multicomponent fate and transport with minimum mass balance error. For single compound model, the kinetic nature of dissolution is increasing with decreasing solubility, even though the peak concentration is always lower than aqueous solubility value. However, when they are present in a mixture, the peak value corresponds to the effective solubility of individual compounds at a particular mole fraction.

The shape of the dissolution profile is significantly influenced by the initial NAPL source strength as well as mean fluid velocity. It is observed that occurrence of high peak concentration for soluble compounds are inversely proportional to the extent of tailing because of the decrease in effective solubility facilitated by the change in mole fraction. For the lesser soluble fractions, the effect of biodegradation is predominant when they reach higher mole fraction in the mixture, which is observed during the descending limb of the profile at higher pore volumes.

The total time required for complete source removal is limited by the solubility of the lowest soluble compounds (ethylbenzene and xylene) and their mole fraction in the mixture. The effect of coupled reactions is minimal for the elution of benzene because of its faster removal caused by high concentration gradient. The sensitivity analysis showed that benzene concentration reached its maximum solubility when the velocity is low $(0.1 \mathrm{~m} /$ day) and NAPL saturation is high (50 percent) resulting in near equilibrium condition with more contact time. The residual NAPL saturation at later times is controlled by the mole fraction of least soluble component.

Mass transfer limitation for the soluble compounds under conditions of low NAPL saturation and low mole fraction is due to low dissolution rate coefficient rather than decreasing concentration gradient. Because of the low solubility and hence low mass transfer rate, practically it is not possible to remove xylene completely from the system under mass transfer limited conditions. The variation of dissolution mass transfer coefficient is found to be highly nonlinear and extending with changing slope for high velocity conditions. The apparent tailing in the concentration of less soluble compounds in the mixture is observed to be due to the declining solubility rather than mass transfer kinetics.

When a multicomponent NAPL system is dissolving, the dynamics of the system, mass transfer rates and the concentration of various compounds in the aqueous phase are quite different in later time periods when compared to early time phenomena. The gradual reversal of mole fractions of the high and low solubility compounds cause these changes which is also carried over to the sorption and biodegradation rates. Models such as this enables us to identify when a specific compound of interest is in significantly high levels and how fast it is removed by taking into consideration the transient mole fractions, mass transfer rates, and associated sorption and biodegradation. These models are advantageous compared to single compound fate and transport models which can over or under-predict aqueous phase concentrations to a large extent. 
However, laboratory scale investigations attempted in the present study would better provide an insight on the effect of variation of porous media properties on the dissolution mass transfer kinetics, which can be highly influential for large scale domain.

\section{Acknowledgements}

The first author would like to thank Mr. M Berlin and Dr. N Natarajan for the help during this study.

\section{References}

Abriola L M 1989 Modeling multiphase migration of organic chemicals in groundwater systems-a review and assessment. Environ. Health Persp. 83: 117-143

Alvarez P J J, Anid P J and Vogel T M 1991 Kinetics of aerobic biodegradation of benzene and toluene in sandy aquifer material. Biodegrad. 9: 43-51

ASTM 1995 Standard guide for risk-based corrective action at petroleum release sites. Standard E 1739

Bekins B A, Warren E and Godsy E M 1998 A comparison of zero-order, first-order and Monod biotransformation models. Groundwater 36(2): 261-268

Bielefeldt A R and Stensel H D 1999 Evaluation of biodegradation kinetic testing methods and long term variability in biokinetics for BTEX metabolism. Wat. Res. 33(3): 733-740

Borden R C and Piwoni M D 1992 Hydrocarbon dissolution and transport: a comparison of equilibrium and kinetic models. J. Contam. Hydrol. 10: 309-323

Brauner J S and Widdowson M A 2001 Numerical simulation of a natural attenuation experiment with a petroleum hydrocarbon NAPL source. Groundwater 39(6): 939-952

Burke W R 2012 Rate limited diffusion and dissolution of multicomponent non-aqueous phase liquids (NAPLs) in groundwater: Masters Dissertation, University of Alabama

Carroll K C and Brusseau M L 2009 Dissolution, cyclodextrin-enhanced solubilization and mass removal of an ideal multicomponent organic liquid. J. Contam. Hydrol. 106(1-2): 62-72

Chamkha A J 2007 Numerical Modeling of Contaminant Transport with Spatially-Dependent Dispersion and Non-Linear Chemical Reaction. Nonlinear Anal: Model. Control. 12(3): 329-343

Chu M, Kitanidis P K and McCarty P L 2007 Dependence of lumped mass transfer coefficient on scale and reactions kinetics for biologically enhanced NAPL dissolution. Adv. Water Resour. 30: 1618-1629

Clement T P, Sun Y, Hooker B S and Petersen J N 1998 Modeling multi-species reactive transport in groundwater. GWMR- spring: 79-92

Clement T P, Guatam T R, Lee K K, Truex M J and Davis G B 2004 Modeling of DNAPL dissolution, rate-limited sorption and biodegradation reactions in groundwater systems. Bioremed. J. 9(1-2): 47-64

Corapcioglu M Y, Yoon S and Chowdhury S 2009 Pore-scale analysis of NAPL blob dissolution and mobilization in porous media. Trans. Porous Med. 79: 419-442

Couto P R L and Malta S M C 2008 Interaction between sorption and biodegradation processes in contaminant transport. Eco. Model. 214: 65-73

Diplock E E, Mardlin D P, Killhama K S and Paton G I 2009 Predicting bioremediation of hydrocarbons: Laboratory to field scale. J. Environ. Pollu. 157: 1831-1840

Essaid I E, Cozzarellib I M, Eganhouseb R P, Herkelratha W N, Bekinsa B A and Delin G N 2003 Inverse modeling of BTEX dissolution and biodegradation at the Bemidji, MN crude-oil spill site. J. Contam. Hydrol. 67: 269-299

Feenstra S 1997 Aqueous Concentration Ratios to Estimate Mass of Multicomponent NAPL Residual in Porous Media. Doctoral Dissertation. Canada: University of Waterloo

Frind E O, Molson J W and Schiemer M 1999 Dissolution and mass transfer of multiple organics under field conditions: The Borden emplaced source. Water Resour. Res. 35(3): 683-694 
Garg S and Rixey W G 1999 The dissolution of benzene, toluene, m-xylene and naphthalene from a residually trapped non-aqueous phase liquid under mass transfer limited conditions. J. Contam. Hydrol. 36: 313-331

Geller J T and Hunt J R 1993 Mass transfer from non-aqueous phase organic liquids in water-saturated porous media. Water Resour. Res. 29(4): 833-845

Gonullu M T 1996 Modeling dissolution of an organic mixture in the subsurface. Water Res., 30(3): 649653

Grant G P and Gerhard J I 2004 Sensitivity of predicted DNAPL source zone longevity to mass transfer correlation model. Geoenviron. Eng: Integr. Manage. Groundwater Contam. Land. R N Young and H R Thomas (eds.), London: Telford Publishing pp. 59-67

Hamed M M, Nelson P D and Bedient P B 2000 A distributed-site model for non-equilibrium dissolution of multicomponent residually trapped NAPL. Environ. Model. Soft. 15: 443-450

Hansen S K 2012 Coupled multi-component NAPL dissolution and transport in the subsurface: analytic solutions and forensic aspects. Doctoral dissertation. Canada: Queen's University

Imhoff P T, Jaffe P R and Pinder G F 1994 An experimental study of complete dissolution of a non-queous phase liquid in saturated porous media. J. Water Resour. Res. 30(2): 307-320

Johnson G R, Zhang Z and Brusseau M L 2003 Characterizing and quantifying the impact of immiscibleliquid dissolution and nonlinear, rate-limited sorption/desorption on low-concentration elution tailing. Water Resour. Res. 39(5): SBH 6(1)-6(8)

Kao C M and Prosser J 2001 Evaluation of natural attenuation at a gasoline spill site. J. Hazard. Mater. B82: 275-289

Keller A A and Sirivithiyapakorn S 2000 Pore Scale Determination of the Rate of NAPL Dissolution or Volatilization. Report (EPA Agreement Number: R826268), University of California, Santa Barbara [http://www.bren.ucsb.edu/ keller/default.html\#Projects]

Kim S, Hwang I, Kim D, Lee S and Jury W A 2003 Effect of sorption on benzene biodegradation in sandy soil. Environ. Toxic.Chem. 22(10): 2306-2311

Kim T J and Chrysikopoulos C V 1999 Mass transfer correlations for non-aqueous phase liquid pool dissolution in saturated porous media. Water Resour. Res. 35: 449-459

Liu L, Tindall J A, Friedel M J and Zhang W 2007 Biodegradation of Organic Chemicals in Soil/Water Microcosms System: Model Development. Water Air Soil Pollut. 178: 131-143

Lovanh N, Zhang Y K, Heathcote R C and Alvarez P J J 2000 Guidelines to Determine Site-Specific Parameters for Modeling the Fate and Transport of Mono-aromatic Hydrocarbons in Groundwater. Report submitted to Iowa Comprehensive Petroleum Underground Storage Tank Fund Board. [http://www. iowadnr.gov/portals/idnr/uploads/ust/monohydrocarbonsguide.pdf]

Maliyekkal S M, Rene E R, Philip L and Swaminathan T 2004 Performance of BTX degraders under substrate versatility conditions. J. Haz. Mater. B109: 201-211

Mayer A S and Miller C T 1996 The influence of mass transfer characteristics and porous media heterogeneity on non aqueous phase dissolution. Water Resour. Res. 32(6): 1551-1568

McCray J E and Dugan P J 2002 Non-ideal equilibrium dissolution of trichloroethene from a decane-based non-aqueous phase liquid mixture: Experimental and modeling investigation. Water Resour. Res. 38(7): $1-9$

Miller C T, Poirier-McNeill M M and Mayer A S 1990 Dissolution of trapped non-aqueous phase liquids: Mass transfer characteristics. Water Resour. Res. 26: 2783-2796

Mobile M A, Widdowson M A and Gallagher D L 2012 Multicomponent NAPL Source Dissolution: Evaluation of Mass-Transfer Coefficients. Environ. Sci. Technol 46: 10,047-10,054

Molson J W 2000 Numerical simulation of hydrocarbon fuel dissolution and biodegradation in groundwater. Doctoral Dissertation. Canada: University of Waterloo

Nambi I M and Powers S E 2000 NAPL dissolution in heterogeneous systems: an experimental investigation in a simple heterogeneous system. J. Contam. Hydrol. 44: 161-184

Nambi I M and Powers S E 2003 Mass transfer correlations for non aqueous phase liquid dissolution from regions with high initial saturations. Water Resour.Res. 39(2): SBH 4, 1-11 
Natarajan N and Suresh Kumar G 2010 Radionuclide and colloid co-transport in a coupled fracture-skinmatrix system. Colloids Surf. A Physicochem. Eng. Asp. 370: 49-57

Powers S E, Abriola L M and Weber W J 1994 An experimental investigation of non-aqueous phase liquid dissolution in saturated subsurface systems: Transient mass transfer rates. Water Resour. Res. 30(2): 321332

Prakash P and Nambi I M 2012 Dissolution and contaminant transport in aquifers with spatially and temporally variable hydraulic properties. Special Top. Rev. Porous Med-Int. J. 3(4): 353-369

Priya V S and Philip L 2013 Bioremediation of dichloromethane along with other VOCs from pharmaceutical wastewater. Appl. Biochem. Biotechnol. doi: 10.1007/s12010-012-0005-1

Prommer H, Davis G B and Barry D A 2000 Biogeochemical transport modeling of natural and enhanced remediation processes in aquifers. J. Land Contam. Reclam. 8(3): 217-223

Renu V and Suresh Kumar G 2012 Numerical Modeling and Spatial Moment Analysis of Solute Mobility and Spreading in a Coupled Fracture-Skin-Matrix System. Geotech. Geol. Eng. 30(6): 1289-1302

Saba T and Illangasekare T H 2000 Effect of groundwater flow dimensionality on mass transfer from entrapped non-aqueous phase liquid contaminants. Water Resourc. Res. 36(4): 971-979

Schaerlaekens Jd, Venderborght J, Merckx R and Feyen J 2000 Surfactant enhanced solubilization of residual trichloroethene: An experimental and numerical analysis. J. Contam. Hydrol. 46: 1-16

Seagren E A, Rittmann B E and Valocchi A J 1999 A critical evaluation of the local-equilibrium assumption in modeling NAPL-pool dissolution. J. Contam. Hydrol. 39: 109-135

Sekhar M and Suresh Kumar G 2006 Modeling transport of linearly sorbing solutes in a single fracture: Asymptotic behavior of solute velocity and dispersivity. Geotech. Geol. Eng. 24: 183-201

Sekhar M, Suresh Kumar G and Mishra D 2006 Numerical modeling and analysis of solute velocity and macrodispersion for linearly and nonlinearly sorbing solutes in a single fracture with matrix diffusion. $J$. Hydrol. Eng. 11(4): 319-328

Soga K, Page J W E and Illangasekare T H 2004 A review of NAPL source zone remediation efficiency and the mass flux approach. J. Hazard. Mater. 110: 13-27

Sulaymon A H and Gzar H A 2011 Experimental investigation and numerical modeling of light nonaqueous phase liquid dissolution and transport in a saturated zone of the soil. J. Hazard. Mater. 186: $1601-1614$

Suresh Kumar G 2008 Effect of Sorption Intensities on Dispersivity and Macro-dispersion Coefficient in a Single Fracture with Matrix Diffusion. Hydrogeol. J. 16: 235-249

Suresh Kumar G 2009 Influence of Sorption Intensity on Solute Mobility in a Fractured Formation. $J$. Environ. Eng., 135(1): 1-7

Suresh Kumar G 2014 Mathematical Modeling of Groundwater Flow and Solute Transport in a Saturated Fractured Rock using Dual-Porosity Approach. J. Hydrol. Eng. doi:10.1061/(ASCE)HE.1943-5584. 0000986

Suresh Kumar G, Sekhar M and Misra D 2008 Time-dependent dispersivity of linearly sorbing solutes in a single fracture with matrix diffusion. J. Hydrol. Eng. 13(4): 250-257

Ucankus T and Unlu K 2008 The effect of aquifer heterogeneity on natural attenuation rate of BTEX. $J$. Environ Geol. 54: 759-776

Vasudevan M, Suresh Kumar G and Nambi I M 2012 Effect of rate limited dissolution and sorption on concentration tailing of multi-component petroleum hydrocarbons from residual sources. Int. J. Earth Sci. Eng. 5, 6(1): 1750-1756

Wang X 2004 A multi-scale study of dissolution, sorption, and biodegradation of a NAPL mixture. Master's dissertation. Canada: University of Toronto

Yadav B K and Hassanizadeh S M 2011 An overview of biodegradation of LNAPLs in coastal (semi)-arid environment. Water Air Soil Pollut. 220(1-4): 225-239

Yang X, Erickson L E and Fan L T 1995 A study of the dissolution rate-limited biodegradation of soils contaminated by residual hydrocarbons. J. Hazard. Mater. 41: 299-313

Zhang Z and Brusseau M L 2004 Non-ideal transport of reactive contaminants in heterogeneous porous media: 7. distributed-domain model incorporating immiscible-liquid dissolution and rate-limited sorption/desorption. J. Contam. Hydrol. 74: 83-103 